\title{
Wh-the-hell as a polarity-insensitive, speaker-oriented domain restrictor*
}

\author{
Joshua Martin \\ Harvard University
}

\begin{abstract}
I argue for a reanalysis of 'wh-the-hell' questions as restrictions on the domain of alternatives, rather than polarity items or domain extensions. This analysis returns to their original characterization as 'aggressively non-D-linked' by specifying what it means to be D-linked, and in doing so captures a number of otherwise unconnected properties of such questions without positing extraneous features. Consequences of the proposal include a new notion of question-specific contextuality, evidence for an inquisitive semantic condition on sluicing, and a potential general discourse restriction on wh-movement.
\end{abstract}

Keywords: 'the hell', D-linking, wh-questions, alternative semantics, polarity, context

\section{Non-D-linked $w h$-questions}

Imagine it is the day of an election, and the results are coming in live. It's a close race, with potential legal challenges to the results. Your friend utters one of: ${ }^{1}$

(1) a. I'm freaking out about who won the election.

b. I'm freaking out about who the hell won the election.

The salient reading of (1a) is that they heard the final result, and are displeased with it, but there is also a reading on which it is the uncertainty of the result freaking them out. Interestingly, (1b) has only the latter reading, and is incompatible with a situation where the speaker knows the true victor. The same contrast holds in the unembedded context, where the non-hell question can be used to request currently unknown information or to express surprise at the answer (with echo intonation), while the hell question lacks the echo option and must be a genuine interrogative.

$$
\text { WHO (*the hell) won the election? }
$$

* I thank Kathryn Davidson, Isabelle Charnavel, Gunnar Lund, Jonathan Bobaljik, C.T. James Huang, Uli Sauerland, Diti Bhadra, Hadas Kotek, and Harvard's Meaning \& Modality Lab for helpful discussions, as well as the reviewers and audience of SALT30 for their insightful questions.

1 Unless otherwise noted, English judgments are from my own intuitions and checked informally with other native speakers. Any discrepancies in these judgments will be made explicit. 
Wh-the-hell as domain restrictor

This paper aims to develop a semantics of the hell to account for its interpretive effects, like (1), and its syntactic restrictions, like (2). This class of $w h$-questions, exemplified by wh-the-hell but including also what the fuck, what on earth, and others, was first described by Pesetsky (1987) as 'aggressively non-discourse-linked'. He argues that 'the whole point of uttering a question like What the hell did you read that in? is to express surprise in the answer. The appropriate answer is presumed not to figure in previous discourse' (Pesetsky 1987: 111). Not just indicating attitude, these constructions have a variety of distributional constraints not straightforwardly captured by such a discourse requirement. Along with being ungrammatical in echo questions as in (2), it is ungrammatical with which (Pesetsky 1987), embedded under some factive verbs (den Dikken \& Giannakidou 2002; Huang \& Ochi 2004), in-situ in single or multiple wh-questions (Obenauer 1994), when pied-piped (Pesetsky 1987; Akiyama 2014), and when sluiced (Merchant 2001: 122):
a. *Which the hell did you buy?
b. *I know who the hell bought it.
c. *Who bought what the hell?
d. *You bought what the hell?

e. *To who the hell did you sell it?

f. I wish I knew who the hell *(it was)!

This collection of behaviors has led theorists to ascribe a wide variety of properties to wh-the-hell, including polarity sensitivity (den Dikken \& Giannakidou 2002), identificational focus (Oguro 2017), and logophoric attitude (Huang \& Ochi 2004; Akiyama 2014). While each of these accounts offers some useful insight, none of them has managed to capture the full empirical picture, I think because of their 'add a new feature' approach. In most of these accounts, 'aggressively non-D-linked questions' has become a category label, a way of referencing the class of wh-the-hell questions, while its contribution as an explanatory aspect has been systematically reduced. The question has become, roughly, 'What other property do aggressively non-D-linked questions have that explains their felicity conditions?'. This approach seems misled. The question, as originally posed and as I raise it again, should rather be 'What is it about the aggressive non-D-linking of these questions that explains their felicity conditions?' A maximally parsimonious theory should explain the behavior of non-D-linked questions in virtue of their being non-D-linked.

My central claim will be that explaining wh-the-hell questions requires only explaining what it means to be non-D-linked. Since this requires formalizing a notion of D-linking, which has resisted formal specification despite its widespread use, wh-the-hell will act as a useful test case for illuminating our understanding of the syntax and semantics of wh-questions more broadly. In Section 2, I argue against the most widely cited account of wh-the-hell, that of den Dikken \& Giannakidou (2002), and establish that wh-the-hell is not a polarity item. In Section 3, I develop 
an analysis on which the hell restricts the domain of alternatives which can serve as possible answers to the question, and show that it captures most of the properties above, and some new ones. Section 4 addresses the persistent problem of in-situ wh-the-hell in multiple questions, proposing a general condition on $w h$-in-situ and linking it to the alternative semantics of questions, and Section 5 concludes.

\section{Against polarity}

A highly influential account of wh-the-hell from den Dikken \& Giannakidou (2002), henceforth DG, posits that wh-the-hell is a polarity item (PI) based on observed parallels between it and known PIs like any. While it is theoretically attractive to assimilate wh-the-hell to the independently needed framework of polarity, it is ultimately untenable, as the parallels with any break down against a wider backdrop of data. DG's separate argument that wh-the-hell is a domain extender will be addressed in Section 3.5; here I focus primarily on the polarity arguments.

\subsection{Veridicality and ignorance}

Uncontroversially, wh-the-hell phrases are restricted with respect to which verbs they may embed under. DG observe that they are ungrammatical under factive or veridical verbs, but become acceptable when those verbs are negated:

(4) a. I*(don't) know who the hell would buy that book.

(DG: 33)

b. He $\{$ didn't tell / *told $\}$ me who the hell bought that book.

This parallels the distribution of the PI anyone:

(5) a. I *(don't) know that anyone would buy that book. (adapted from DG: 34)

b. He $\{$ didn't tell / *told $\}$ me that anyone bought that book.

And, both the hell and the PI are licensed in many nonveridical environments:

(6) a. I wonder who the hell bought that book.

(adapted from DG: 34) $\ldots$ if anyone ...

b. He refused to tell me who the hell bought that book.

$\ldots$ if anyone ...

c. Nobody knows who the hell bought that book.

... if anyone ...

d. Only he knows who the hell bought that book.

$$
\ldots \text { if anyone ... }
$$


Wh-the-hell as domain restrictor

e. If he knows who the hell bought that book, he should tell us now.

$\ldots$ if anyone ...

DG conclude from this that their licensing conditions are the same, and thus that this data argues in favor of wh-the-hell being a PI. However, note that the only predicates which rule out wh-the-hell are the positive factive ones, I know... and He told me... All of the other environments share another discourse feature: they ensure that the speaker does not know the answer to the question. If I am wondering who bought the book, or you refuse to tell me, or nobody knows, or only you know, it is clear that I do not know. This factor is obviously irrelevant for licensing a PI, as we can illustrate by swapping the first and third-person pronouns.

(7) a. He doesn't know that anyone would buy that book.

b. I didn't tell him that anyone bought that book.

a. He wonders if anyone bought that book.

b. I refused to tell him if anyone bought that book.

c. Nobody but me knows if anyone bought that book.

d. Only I know whether anyone bought that book.

e. If I know if anyone bought that book, I should tell him now.

Crucially, however, it is relevant for wh-the-hell. Not every context will show this, since it may be difficult to guarantee first-person ignorance of the answer, e.g. He wonders... says nothing about the speaker's knowledge either way. Still, when the environment implies the speaker does know the answer, wh-the-hell is ruled out.

(9) a. *I refused to tell him who the hell bought that book.

b. *Nobody but me knows who the hell bought that book.

c. *Only I know who the hell bought that book.

Guaranteeing speaker ignorance, such as through contrastive focus as in (10), also allows wh-the-hell (but not any) to embed under a non-negated factive.

(10) a. HE knows who the hell bought that book, but he won't tell me. ... *that anyone ...

b. HE told his brother who the hell bought that book, but not me.

... *that anyone ...

No theory of polarity predicts sensitivity to this. Per DG, (10) alone is enough to rule out $w h$-the-hell being a PI: 'there is one distributional constraint that all the PI paradigms must obey in order to qualify for PI status: they must be inadmissible in 
the scope of veridical operators.' (DG: 37) The only exception is another purported parallel between wh-the-hell and any, namely that they can be under factives when there is a 'negative implicature' (Giannakidou 1999):

(11) NOW I know who the hell stole my car. Negative implicature: I did not know before.

(12) I am surprised she has any friends. Negative implicature: I didn't expect her to have any friends.

However, this conflates two flavors of 'negative implicature' which should be regarded as distinct. In particular, the 'I did not know before' implicature of focused NOW licenses wh-the-hell, but not any, as in (13). Conversely, the 'I didn't expect' implicature of surprise licenses any, but not wh-the-hell, as in (14).

(13) *NOW I know (that) she has any friends. Negative implicature: I did not know before.

(14) *I am surprised (by) who the hell stole my car.

Negative implicature: I didn't expect them to have stolen my car.

It is thus incorrect to conclude 'that wh-the-hell behaves like other PIs in this respect' (DG: 39). This provides a double dissociation between wh-the-hell and any: we have shown environments where the former is licensed but not the latter, such as (10) and (11) vs. (13), and where the latter is licensed but not the former, such as (8) vs. (9) and (12) vs. (14). Regardless of whether analyzing wh-the-hell as a PI would capture its other behavior, then, the path is too hazardous to tread.

\subsection{Negative attitude}

Briefly, DG also give wh-the-hell a presupposition of negative attitude, 'a modalized conditional statement saying that if any $x$ such as $x$ did what is expressed by the VP, then $x$ should not have done it' (DG: 43). So, the presupposition of (15a) is (15b).

a. Who the hell talked to Ariadne? (den Dikken \& Giannakidou 2002: 43)

b. If there is a person $x$ in $w$, and $x$ talked to Ariadne in $w: x$ should not have talked to Ariadne in $w$.

But this is too strong. It is easy to imagine contexts where (15b) does not hold, e.g. if every student in a class was supposed to be interviewed and have a report written about them, but the report about Ariadne is missing, even though she insists someone did interview her, a teacher might utter (15a) with the intention that someone absolutely should have. In contexts like our election example (1), it is not 
Wh-the-hell as domain restrictor

the case that you don't think anyone should win the election. Positive attitude is also possible; imagine that you've failed to get tickets to see a sold-out show but I miraculously found some at the last minute. You might say How the hell did you do that? and be quite happy that I did so. This is all just to say that negative attitude should not be encoded into wh-the-hell. It can be derived in many cases, simply from the interaction of wanting to know the answer and being unable to find it.

\section{Semantic analysis}

In this section, I build an analysis of wh-the-hell, following the intuitions developed in the previous section regarding speaker ignorance. This property was initially ascribed to wh-the-hell by Oguro (2017), though in his formulation, it simply meant that the speaker did not know the answer to the question, which will be too weak. Here, I argue for a particular flavor of speaker ignorance, not just of the particular answer, but in a sense of what the answer could even be. Before that, though, I will (very briefly) introduce the framework for the semantics of questions adopted here.

\subsection{Background}

I will be largely adopting Kotek's (2018) implementation of Beck's (2006) semantics for questions (see also Beck \& Kim 2006; Cable 2010). The idea that the meaning of a question consists of the set of its possible answers (Hamblin 1973) is instantiated in terms of alternatives in the focus-semantic domain. Specifically, wh-words contribute no ordinary semantic meaning (are undefined in the ordinary domain), and their focus-semantic meaning is a set of alternatives composed of the possible answers to the question. Thus, all $w h$-words denote Hamblin sets, and $w h$-words differ in the types of alternatives the set they denote contains.

a. Ordinary value: $\llbracket$ who $\rrbracket^{o}$ is undefined

(Kotek 2018: 31) Alternative value: $\llbracket$ who $\rrbracket^{f}=\left\{x_{e}: x \in\right.$ human $\}$

b. Ordinary value: $\llbracket$ what $\rrbracket^{o}$ is undefined Alternative value: $\llbracket$ what $\rrbracket^{f}=\left\{x_{e}: x \notin\right.$ human $\}$

Other $w h$-words contribute similar restrictions on alternatives, i.e. when considers times, where locations, etc. The computation of alternatives in the focus domain occurs in parallel to the computation of ordinary semantic values, as proposed by Rooth (1992). To ensure the question has an ordinary semantic value at LF, Kotek introduces the operator ALTSHIFT, 'the source of interrogative semantics' (Kotek 2018: 32), shifting the alternatives of its complement from the focus domain to the ordinary domain. The output of ALTSHIFT is a set of ordinary semantic propositions, 
and acts as the input to Dayal (2016)'s answerhood operator ANS, which presupposes that a question has a unique maximally informative true answer, and returns it.

\subsection{The proposal: the hell as a restricted domain of alternatives}

I propose that the hell be seen as an additional filter on the alternative sets generated by $w h$-words, roughly one which eliminates all possible answers with which the speaker is familiar. This is implemented through a rather simple semantics, in (17).

$$
\llbracket \text { the hell } \rrbracket^{f}=\overline{\mathbb{C}}
$$

A few things to note. First, this gives the hell only a focus-semantic value, like any $w h$-word. Second, the focus-semantic value is the complement to a set $\mathbb{C}$. I define $\mathbb{C}$ as the context set over alternatives, that is, the set of contextually available alternatives. More on that just below, but for now, this means that the denotation of the hell is the set of contextually unavailable alternatives. This makes it the same type as a $w h$-word, which I will argue is a desirable outcome. So, the composition of a wh-the-hell phrase is simply the intersection of the two alternative sets.

$$
\llbracket \text { what the hell } \rrbracket^{f}=\llbracket \text { what } \rrbracket^{f} \cap \llbracket \text { the hell } \rrbracket^{f}=\left\{x_{e}: x \notin \text { human }\right\} \cap \overline{\mathbb{C}}
$$

So what is $\mathbb{C}$ ? It may be thought of as the set of possible answers to a question which are naturally given as possible in the context, where the context includes common ground both in terms of the discourse and world knowledge. So an answer need not be discourse-familiar to be contextual. $\mathbb{C}$ is thus distinct from, and might be considered the focus-semantic equivalent of, our familiar context set $\mathrm{C}$.

Why is this distinction desirable? Formally, it is necessary to work with the context in the focus-semantic domain, in which case we may want it to be just a typelifted version of $\mathrm{C}$. But I think that there are more intuitive reasons to treat them as distinct objects: namely, just because you are in the context, doesn't mean I consider you a possible answer. The intuition captured by $\mathbb{C}$ is that the set of individuals who are natural, likely referents in a discourse is not necessarily identical to the set of individuals who are natural, likely answers to a given question. Consider:

Who the hell stole my car?

If you have a dog, odds are that you are quite likely to refer to them, especially at home. But if you utter (19), you are likely not considering your dog as a possible answers. The point being, an individual may be in the discourse context as a referent but not in the discourse context as a car thief. When we utter a question like (19), we are not communicating that all individuals in the context have been determined to be untrue answers; rather, that all likely car thieves seem to be untrue answers. 
Wh-the-hell as domain restrictor

This notion of $\mathbb{C}$ is admittedly underspecified. How one determines how to divide the space of possible answers between $\mathbb{C}$ and its complement may never be fully answerable in a formal sense. But semantic theory has readily acknowledged the necessity to encode certain features of the context: the discourse participants, the set $\mathrm{C}$ of individuals in the context, intensional variables to represent the world, something like the QUD stack (Roberts 2012), and perhaps more. Membership in $\mathbb{C}$ is, I think, no more or less specified than membership in $\mathrm{C}$ is.

Before we move on and apply the analysis to capturing wh-the-hell's distribution, note also that this semantics does not encode an existential presupposition into $w h$ the-hell questions. (Szabolcsi \& Zwarts 1993: 261) argue that there is one, and that wh-the-hell questions can only be asked if there is 'unquestionable evidence' that there is a true answer. This seems much too strong, and to me it seems that rhetorical uses are common with wh-the-hell questions, especially with modals. The answer nobody is the expected one for questions like:

\section{Who the hell would buy a book like that?}

Rather, our semantics encodes a local anti-existential presupposition - there may or may not be a true answer, but if there is, it's not one that I am familiar with. From this, we can pragmatically derive the feeling that wh-the-hell questions are asked when we strongly expect an answer. Since the question implies no true answer is in the context, it would be strange to ask it if you did not have reason to believe that one existed somewhere. Otherwise, you intend to utter an unanswerable question.

\subsection{Wh-less $w h$-questions}

You might ask, why give the hell the same type as a $w h$-word, rather than treat it as a function taking a $w h$-word as an argument? Motivating this decision is another intriguing property of the hell, its ability to license deletion of the wh-word.

(21) a. The hell was that?

[COCA, FBI, season 1 episode 18]

b. The hell you doin' in here? [COCA, The Passage, season 1 episode 8]

It can also be used on its own, with a meaning equivalent to what the hell.

(22) The hell?

In fact, only readings where the elided wh-word would be what are allowed.
a. *Someone left. Who the hell was it?
b. *He left it somewhere. Where the hell was it? 
Treating these cases as the only instance of $w h$-ellipsis in the grammar is a tall order, which would be necessary if the hell was a function over alternative sets. But (17) lets the hell fill the role of a wh-word on its own. This also explains the whatpreference, since nothing in $\llbracket$ the hell $\rrbracket$ triggers an interpretation targeting people or locations. We thus default to the least marked set. Note, however, that it does not bear the $[+w h]$ feature, syntactically, as it cannot be embedded:

*I don't know the hell is going on.

Additionally, this is only possible for the definite non-D-linked constructions, suggesting that perhaps the prepositional ones are, indeed, functions over $w h$-words.

$*\{$ On earth/In the hell $\}$ is going on?

\subsection{Speaker ignorance}

(17) implicitly encodes speaker orientation. Contextual availability is dependent on the common ground of the discourse participants, and necessarily relative; available to me, as the asker. Thus, ignorance follows from the anti-contextual filtering of the hell: any answer the speaker knows is a member of $\mathbb{C}$. This derives the contrasts in Section 2.1. This section further develops our notion of speaker ignorance.

\subsubsection{Absence of perspective shift}

The sensitivity that the hell shows to the speaker's knowledge state is not logophoric. Some perspectival elements shift whose perspective they represent when embedded in clauses with different attitude holders or perspective takers as subjects. The hell is not one of these - it represents the doxastic alternatives of the utterance speaker, even when embedded underneath an alternate attitude holder.

(26) a. Sam doesn't know who the hell that was. (\#But I do.)

b. Sam believes that they'll catch whoever the hell it was. (\#It was me.)

The only instances of shift are embedding under a verb of speech:

a. Sam asked me who the hell that was, so I told her.

b. Sam said she didn't know what the hell was going on, but I do.

We might analyze these as a kind of quotation or indirect discourse, which changes the 'speaker' rather than merely the perspective taker. This is problematic for analyses like that of Huang \& Ochi (2004) and Akiyama (2014), who posit that the hell is sensitive to logophoric attitude or a syntactic point-of-view projection, 
Wh-the-hell as domain restrictor

respectively. Huang \& Ochi (2004) show that Mandarin daodi and Japanese ittai do undergo this kind of logophoric shift, and argue for a uniform analysis with English wh-the-hell. But such uniformity is ill-advised given (26). Similarly, Akiyama (2014) argues that the hell enters the derivation unvalued for syntactic POV features, which must be valued by a POV head accessible in the same phase (Chomsky 2008). But this analysis makes incorrect predictions for data like (28):

(28) Blake knows that Alex won't tell me what the hell is going on.

$[P O V=S p k r$ B knows [POV=Blake that A won't tell me [POV=Alex what...]]]

In (28), the hell should be able to be valued by the POV features of its clausal subject Alex, or perhaps the subject of the higher clause, Blake, if wh-the-hell is in the phase edge and thus accessible outside of the local clause. But neither of these interpretations are available: the ignorance conveyed by the hell is the actual speaker's, despite the POV projection of the speaker being too distant for Agree.

\subsubsection{Contextual questions}

Anti-contextuality predicts that the hell be incompatible with constructions that require a contextually available answer. This seems to hold for a number of examples.

(29) Since when (*the hell) do you have tenure?

Kiss (2017) says that Since when p? can be paraphrased as Since when is it (or should it have been) part of our common ground that p? Thus, a since when question implies that the proposition being questioned is intended by the addressee to be in the common ground. Given that a specific discourse-salient proposition is necessarily in $\mathbb{C}$, it is incompatible with the hell.

(30) Guess what (*the hell) I'm doing tonight.

Guess-constructions like (30) have a stronger presupposition: the speaker knows the true answer to the wh-question. This is, trivially, incompatible with the hell.

\subsubsection{Kind questions}

Though the hell is degraded with NP complements, kind of alleviates it.

What the hell *(kind of) book are you reading?

Akiyama (2014) offers a syntactic explanation, in which he analogizes kind of phrases syntactically to measure phrases. But, this does not explain the infelicity without kind, and it inaccurately predicts the hell to be allowed in measure phrases. 
*What the hell $\{$ some/half/two $\}$ of the books did you read?

The only grammatical equivalents are those which are synonymous.

What the hell $\{$ type/sort $\}$ of book are you reading?

Thus, the analysis for the contrast in (31) should not be syntactic. I propose a pragmatic account to derive it from the hell's semantics, in the following way. Given that the use of the hell in a question indicates that the speaker does not have any contextually available alternatives which they believe could be an answer to the question, replying with a specific individual is uncooperative, as that individual will necessarily be unfamiliar to the speaker, and so will be contribute no useful information. Instead, answers which reference properties are more interpretable.

\subsubsection{Rogative preference}

Recall from 2.1 that the hell is compatible with rogatives like wonder, but incompatible with surprise. This is true even if speaker ignorance is guaranteed.

(34) I don't know who won, but Riley seems surprised by who (*the hell) it is.

So, we cannot assimilate this to our general ignorance requirement. Note instead that surprise has a complementary distribution with wonder (Karttunen 1977). Only the former can embed a declarative, and only the latter can embed if-clauses. Surprise $+w h$ can only have the reading of being surprised by the answer, and wonder can only mean wondering what the answer is. This suggests that surprise selects for an answer, while wonder selects for the interrogative itself. When the embedding verb is ambiguous, wh-the-hell only allows the latter reading, as in (1).

We can explain this via the interaction of ANS and the hell. Though Ans can select the maximally informative true answer from $\overline{\mathbb{C}}$, it will still be contextually unavailable - ANS 'knows' it exists, but cannot make it discourse-available. Surprise, which requires an available answer, will be unable to select such an output. Wonder doesn't need the answer. We could say that rogatives embed a question without ANS, selecting directly for a Hamblin set, but I will not develop this idea further here.

\subsubsection{Ignorance implications}

While the general claim from DG that negative implicatures license wh-the-hell is too strong, this notion is useful to explain another pattern. pecifically, predicates vary on the kind of ignorance implication that they generate out of the blue, and this corresponds to a spectrum of acceptability with embedded wh-the-hell.

a. I \{found out/discovered $\}$ who the hell stole my car. 
Wh-the-hell as domain restrictor

b. ?I \{confirmed/realized $\}$ who the hell stole my car.

c. $* I\{$ heard/was told $\}$ who the hell stole my car.

(35a) strongly implies the subject did not know the embedded proposition before, and underwent some search to find the answer. (35b) does so to a lesser extent, and (35c) has no implication of past ignorance. These judgments, however, are sensitive to contextual manipulation. Observe that they can all embed wh-the-hell if they are modified by finally, which provides the necessary ignorance implication by itself.

\subsection{Defending domain restriction}

The main thrust of this analysis is that wh-the-hell should be seen as restricting the $w h$-word's domain of quantification, rather than expanding it. This contrasts with DG's approach, which says that the hell 'extends the domain of quantification' of the $w h$-word 'to include familiar and novel values', and as a result, 'the domain of quantification for wh-the-hell is the entire domain $\mathrm{D}$, and not just a presupposed subset of it, as with regular wh-words.' (DG: 43). Then, a scalar inference is triggered such that wh-the-hell implies the answer is in the extended domain. This argument is independent from the polarity concerns, so it needs its own treatment.

\subsubsection{The wh-typology}

My primary argument is this: treating wh-the-hell as domain expansion allows a contrast between it and what, but not between what and which. It undesirably collapses the typology of $w h$-questions and strands those $w h$-words which are neither aggressively D-linked nor non-D-linked. The scalar inference DG describe needs to run between what and which to derive their behavior: what quantifies over the whole domain, and which over the local subdomain, so the use of what implies a less familiar answer. Adding the hell, instead, restricts what to the non-local domain, which also predicts * which the hell, something not derived by the expansion account.

This is required for when they both take an NP complement. Imagine that a professor has assigned students to each read a paper, but let them choose which one. If the professor provides a restricted list, (36b) is preferred and (36a) is marked. With no relevant list, the inverse holds. If both options are available, from a list or your own choice, (36b) implies you used the list and (36a) the opposite.

(36) a. What paper did you choose?

b. Which paper did you choose?

c. What the hell did you choose? 
In all contexts, (36c) not just implies, but requires the speaker believe the addressee chose an unknown paper. This pattern cannot be derived by the expansion account of wh-the-hell. Additionally, it motivates the inclusion of a contextual

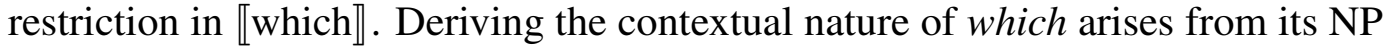
complement fails to predict the divergent behavior of what NP and which NP.

\subsubsection{So-called D-linked uses}

An obvious problem for the domain restriction account, on the other hand, is the existence of evidently D-linked uses of wh-the-hell:

What the hell is the right answer? (to a multiple choice question) (Oguro 2017: 117)

(38) Who on earth will they pick? (in a reality show)

(Rawlins 2008: 196)

In these examples, there is a defined list of possible answers. However, I would argue that they are only licit if the speaker has reason to reject every answer. (37) is only acceptable if you have already, for example, plugged each answer into the formula and gotten the wrong output every time; it would be infelicitous said out of the blue upon encountering the question. Similarly, (38) is only acceptable if no contestant is a viable winner. While Rawlins compares it to Whoever will they pick?, he also acknowledges that 'In the case of the expletive question, the speaker might also be suggesting that it seems implausible that they could choose anyone at all'. This is the key difference: -ever suggests ignorance between the possible answers, which is possible if they have all performed well as in the context he provides, while the hell suggests that none seem viable. In this way, using wh-the-hell in a supposedly D-linked context is a pragmatic move to declare your lack of belief in the provided answer set, while -ever only suggests you cannot decide between them.

Additionally, Rawlins' intensional domain widening, while more persuasive than DG's extensional widening, still fails to make certain relevant predictions. In the next sections, I will argue that it is the fact that wh-the-hell actually excludes the context that explains its behavior with which, non-fronted questions, and sluices.

\section{6 *Which the hell}

Based on the arguments above, I revise Kotek's semantics for which to include an explicit contextual restriction, rather than assuming it is provided by the NP.

$$
\llbracket \text { which } \rrbracket^{f}=\lambda P_{\langle e, t\rangle} \cdot \lambda x_{e} \cdot P(x) \wedge x \in \mathbb{C}=\lambda P_{\langle e, t\rangle} \cdot P \cap \mathbb{C}
$$

We could instead stipulate that which only combines with NPs carrying a contextual restriction, but that feels like quite the same move. Now, the set denoted by 
Wh-the-hell as domain restrictor

which NP is a subset of the set denoted by what NP. This allows the scalar inferences as described in Section 3.5 to proceed as intended. The incompatibility of which and the hell should also now be obvious. Since which filters out alternatives not in $\mathbb{C}$, and the hell filters out alternatives in $\mathbb{C}$, the result will be the empty set.

$\llbracket$ which the hell $\rrbracket^{f}=\llbracket$ which $\rrbracket^{f} \cap \llbracket$ the hell $\rrbracket^{f}=\mathbb{C} \cap \overline{\mathbb{C}}=\emptyset$

The derivation will then crash at ANS. Another consequence of this discussion is that which, and thus $\mathbb{C}$, imposes a looser restriction than the discourse familiarity or salience requirement of a definite. This is desirable, given that (41a) is licit in contexts that (41b) is not: only the latter requires a salient subset of countries.

a. Which countries did you visit?

b. Which of the countries did you visit?

\subsection{Single in-situ questions}

Recall that wh-the-hell cannot be in-situ, as in (3d), or echoed, as in (2). Both of these can be derived from the anticontextuality requirement, at least for single wh-questions; we'll return to multiple questions in Section 4.

\subsubsection{Non-echo questions}

Pires \& Taylor (2007) and Bobaljik \& Wurmbrand (2015) both observe that single wh-questions may occur non-fronted even when not echoed in English. Such constructions are felicitous, it seems, only when there is the assumption that the listener knows the answer already.

(42) a. I was driving along Andrews Avenue.

(Pires \& Taylor 2007)

b. And you were driving in which direction?

a. So, your boy's name is what?

[McNulty, The Wire, S1E1]

b. You've been in this post how long, exactly? [Harry Potter and the Order of the Phoenix, Ch. 15]

Bobaljik \& Wurmbrand (2015) argue that such questions lack interrogative syntax, as they cannot embed under the same predicates as fronted $w h$-questions. In the absence of a clausal $\mathrm{C}_{[+W h]}$, then, the in-situ $w h$-phrase carries a phrasal $Q$ feature. Interrogative semantics is triggered pragmatically: the wh-word, like an indefinite, triggers a set of alternatives. Unlike an indefinite, however, the wh-word contributes no ordinary value, and so it acts as a sort of placeholder in the sentence, prompting the listener to choose between the proffered alternatives. This pragmatic reasoning only functions if the speaker can assume the listener knows the true answer, and thus implies a contextuality requirement incompatible with the hell. 


\subsubsection{Echo questions}

Beck \& Reis (2018) give a compelling analysis of echo questions on which there is also no clausal interrogative syntax, the echo $w h$-phrase has a phrasal Q, and it is the narrow focus on the $w h$-word which triggers interrogative semantics: 'Focus marking... triggers the introduction of alternatives... In the case of narrow focus on $w h$, there is - unusually - one particular alternative, namely the deictic or anaphoric alternative to the $w h$-element... Focus, as always, requires a (adjacent) discourse antecedent. Thus the deictic/anaphoric alternative has to be available in the context.' (Beck \& Reis 2018: 16) Thus, the meaning of an echoed $w h$-word is as in (44), and this results in a clash with the hell as in (45), giving an unanswerable question.

$$
\begin{aligned}
& \llbracket \text { WHAT } \rrbracket^{f}=\{z\} \text { (where } z \text { is the unique contextually relevant element of } D_{e} \text { ) } \\
& \llbracket \text { WHAT the hell } \rrbracket^{f}=\llbracket \text { WHAT } \rrbracket^{f} \cap \llbracket \text { the hell } \rrbracket^{f}=\{z\} \cap \overline{\mathbb{C}}=\emptyset
\end{aligned}
$$

\subsection{Sluicing}

Since Merchant (2001), it has been noted that wh-the-hell cannot be sluiced.

(46) Someone bought this book, but I don't know who (*the hell).

DG attribute this to an inability to establish an anaphoric link between whthe-hell and the discourse-familiar someone, following from the assumption that wh-the-hell does not carry an index. But this analysis cannot be correct, given that wh-the-hell can be linked anaphorically to an indefinite or definite NP:

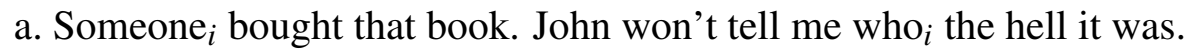

b. I've trailed the thief ${ }_{i}$ for weeks and I still don't know who ${ }_{i}$ the hell he is.

Thus, we need an independent account of the sluicing fact. Syntactic identity accounts like Rudin (2019) will not do, since the elided material in (46) is the same with or without the hell. The semantic identity account in Merchant (2001), which requires symmetric entailment between the elided material and its antecedent, will also fail, since the truth conditions of the elided material are also the same as the antecedent, in virtue of the hell contributing no ordinary meaning.

We can find what we need in the inquisitive semantic account of AnderBois (2014), who notes that the only acceptable antecedents for sluicing are those which are inquisitive (introduce alternatives). Observing that sluicing is not licensed where two clauses are truth-conditionally identical but introduce different alternatives, AnderBois revises Merchant's symmetric entailment condition in two ways. First, entailment is defined over alternatives, mirroring Groenendijk \& Stokhof (1984): 
Wh-the-hell as domain restrictor

$$
\phi \models \psi \text { iff } \forall \alpha \in \llbracket \phi \rrbracket, \alpha \text { is s.t. } \exists \beta \in \llbracket \psi \rrbracket \text { s.t. } \alpha \subseteq \beta \quad \text { (AnderBois 2014: 899) }
$$

The second revision is that the symmetric entailment condition holds not of the elided IP and its antecedent IP, but of the CPs containing them.

SYMMETRIC ENTAILMENT CONDITION ON SLUICING: Given a structure $\left[C P_{E}\left[C+Q I P_{E}\right]\right], I P_{E}$ can be elided only if there is some salient antecedent $C P_{A}$ such that $C P_{E}=C P_{A}$, and $C P_{A} \models C P_{E}$.

(AnderBois 2014: 900)

Combined with (17), this straightforwardly derives the sluicing ban. Consider (46). Symmetric entailment is trivial with who condition, as the alternatives of who and someone are identical (Kratzer \& Shimoyama 2002). Thus, since «who $\rrbracket^{f}$ $=\llbracket$ someone $\rrbracket^{f}$, (48) will be trivially satisfied, and since the rest of the clause is identical, (49) will be as well. For each alternative $\alpha$ in $\llbracket$ someone bought this book》, an alternative $\beta=\alpha$ exists in $\llbracket$ who bought this book》.

This is not the case with who the hell. As we saw before, while $\llbracket$ who $\rrbracket^{f}$ is contextually unconstrained, $\llbracket$ who the hell $\rrbracket^{f}=\llbracket$ who $\rrbracket^{f} \cap \overline{\mathbb{C}}$, such that the set of alternatives introduced by who the hell is strictly a subset of the set introduced by who, and thus of the set introduced by someone. Since $\llbracket$ someone $\rrbracket^{f}$ includes alternatives in both $\mathbb{C}$ and $\overline{\mathbb{C}}$, there will necessarily be alternatives it introduces which do not have a corresponding alternative in $\llbracket$ who the hell $\rrbracket^{f}$, which contains solely alternatives in $\overline{\mathbb{C}}$. Formally, $\forall \alpha \in \llbracket$ someone $\rrbracket^{f}\left[(\alpha \in \mathbb{C}) \rightarrow \neg \exists \beta \in \llbracket\right.$ who the hell $\rrbracket^{f}$ s.t. $\alpha \subseteq \beta$ ]. Thus, (49) will never be satisfied in this case where $C P_{E}$ is a subset of $C P_{A}$, since $C P_{E}=C P_{A}$ will always be true but $C P_{A} \models C P_{E}$ will never be.

No account of sluicing not referencing alternatives will be able to capture (46).

\section{D-linking and multiple in-situ}

Finally, this section considers the ban on the hell in the lower position of a multiple wh-question, as in (3c), and proposes assimilating it to a more general restriction. To set up our discussion of multiple questions, let's look at one more illustrative pattern. Certain adverbs of quantity and frequency are incompatible with wh-the-hell.
a. *I \{largely/mostly/usually/rarely/often $\}$ don't know who the hell cheats.
b. *For the most part/With few exceptions, I don't know who the hell cheats.

But no such problem with never, or with always outside the scope of negation:
a. I never know who the hell cheated.
b. I always find out who the hell cheated.
c. *I don’t always know who the hell cheated. 
Per Lahiri (1991), such adverbs, modifying question-embedding predicates, quantify over parts of the complete answer to the question, e.g. mostly means that you know most of the parts of the answer. The relevant insight is that they require quantification over individual sub-answers composing a larger answer, where such sub-answers will be individual alternatives. Since the alternatives introduced by wh-the-hell are unavailable to the speaker, the ability to access individual sub-parts of the complete answer will be restricted. So, the acceptable forms of quantification address the entire set at once - (51a) and (51b), both universal quantification - but as soon as you need to 'look into' the set and accept or reject specific parts, those parts would need to be available to you. So, existential quantification like (51c) or most-type quantification like (50) cannot occur over wh-the-hell.

The intuition that we are unable to evaluate individual possible answers with wh-the-hell is, I think, critical to what D-linking actually is. I want to adopt an idea mentioned in passing by Comorovski, that 'the use of D-linked $w h$-phrases requires that the participants in the conversation be able to partition identically the set that the wh-phrase ranges over' (Comorovski 1996: 13). This is partitioning not in the G\&S sense, but rather the mutual division of the set of possible answers by speaker and hearer into pieces of equal size. This identical partitioning requirement is trivial with contextually available sets, like which $N P$, since the maximum partition into singletons is always possible with known members. Conversely, wh-the-hell can never be D-linked in this sense, as the subparts of $\overline{\mathbb{C}}$ are unknown.

D-linking on this view is a gradient property of the context, not a binary feature of $w h$-words. Different $w h$-words will be differentially D-linkable, by how naturally discrete the answers they range over are, on a spectrum between which and whthe-hell. The individuals ranged over by who are easily partitioned, and treated as atomic; locations in where are generally discrete; and the sets of reasons and manners denoted by why and how will be difficult to D-link absent rich abnormal context. 'Aggressive' non-D-linking, then, is just the extreme case, a semantics which precludes such individuation; and the inverse for which, which guarantees it.

What I want to draw attention to is that this spectrum correlates with in-situ acceptability. While which can always be in-situ, and wh-the-hell never is, other whwords vary based on D-linkability. To illustrate, imagine two versions of a cooking competition. In one, cooks prepared dishes which are now lined up anonymously in front of judges, and after evaluation, the judges ask the cooks to come forward and stand next to their dish. In another, it is the contestants who are lined up and the dishes hidden, and judges ask each cook to retrieve and present their dish. Only in the former context, where the dishes are known, is (52) an acceptable question.

Who made what?

Similarly, in-situ where is gradiently improved with more identifiable answers. 
Wh-the-hell as domain restrictor

(53) Asking colleagues about their summer travel destinations: Who went where?

a. $\checkmark$ Students went to one of five designated countries for study abroad.

b. ? Linguists conducted fieldwork in potentially any country in the world.

c. \# NASA travelers documenting previously unknown parts of the universe.

Even why and how, claimed to be impossible in-situ because they are Merged high (Rizzi 1990; Stepanov \& Tsai 2008), can be tolerated if the context provides a clear individuation of the possible answers.

(54) Contestants restricted to one of three specified methods for cooking, selected ahead of the challenge: ?Who cooked their dish how?

(55) Contestants divided into teams based on their choice of one of three provided reasons: ?Who is competing why?

All I can do here is suggest that this pattern may indeed be generalizable, but if true, it allows us to assimilate the ban on in-situ wh-the-hell to a more general one. But why? If non-D-linked $w h$-phrases can generally not be in-situ, our explanation cannot reference a specific feature of wh-the-hell, and reducing the wh-the-hell problem to a general one is all that is in our scope for this paper about wh-the-hell. So, more questions than answers. But Kotek (2018) offers us a potential out, arguing based on focus intervention effects that no in-situ $w h$-phrases undergo covert movement to $\mathrm{CP}$, but rather are interpreted via a long-distance focus computation, composing alternatives via pointwise FA. With limited space, here is the briefest of gestures towards a proposal: at-a-distance FA in the focus domain, being pointwise, may require such individuated alternatives in Comorovski's sense. This has immediate intrigue and problems; consider it an open invitation to see where it goes.

\section{Conclusion}

I have offered an account of wh-the-hell as a restricted domain of anti-contextual alternatives, taking seriously the idea of non-D-linking as its fundamental property, which is empirically superior to a polarity-based account. It predicts wh-the-hell's embedding behavior, its restrictions on wh-positions, and its inability to be sluiced, thus arguing in favor of an inquisitive theory of sluicing. It also introduces a new notion of a question-specific context. It proposes assimilating the ban on wh-the-hell in-situ to a general ban on non-D-linked phrases, and opens up the question of how context, focus alternatives, and $w h$-movement rules interact to generate such restrictions. In doing so, I hope to have shown that wh-the-hell is an illuminating test case for interrogative syntax and semantics, rather than a fringe phenomenon. 


\section{References}

Akiyama, Masahiro. 2014. A formal characterization of the hell as a marker of bafflement and phase impenetrability. Sophia Linguistica 61. 1.

AnderBois, Scott. 2014. The semantics of sluicing: beyond truth conditions. Language 90(4). 887-926. doi:10.1353/lan.2014.0110.

Beck, Sigrid. 2006. Intervention effects follow from focus interpretation. Natural Language Semantics 4. 1-56. doi:10.1007/s11050-005-4532-y.

Beck, Sigrid \& Shin-Sook Kim. 2006. Intervention effects in alternative questions. Journal of Comparative Germanic Linguistics 9. 165-208. doi:10.1007/s10828006-9005-2.

Beck, Sigrid \& Marga Reis. 2018. On the Form and Interpretation of Echo WhQuestions. Journal of Semantics 35(3). 369-408. doi:10.1093/jos/ffy002.

Bobaljik, Jonathan \& Susi Wurmbrand. 2015. Questions with Declarative Syntax Tell us What about Selection? In Ángel J. Gallego \& Dennis Ott (eds.), 50 Years Later: Reflections on Chomsky's Aspects, vol. 77 MIT Working Papers in Linguistics, 13-31. Cambridge, MA: MIT.

Cable, Seth. 2010. The grammar of Q: Q-particles, wh-movement, and pied-piping. Oxford: Oxford University Press.

Chomsky, Noam. 2008. On phases. In Robert Freidlin, Carlos P. Otero \& Maria Luisa Zubizarreta (eds.), Foundational issues in linguistic theory: Essays in honor of Jean-Roger Vergnaud, 133-167. Cambridge, MA: MIT Press.

Comorovski, Ileana. 1996. Interrogative Phrases and the Syntax-Semantics Interface, vol. 59 Studies in Language \& Philosophy. Dordrecht: Springer Netherlands.

Dayal, Veneeta. 2016. Questions Oxford Surveys in Semantics and Pragmatics. Oxford: Oxford University Press.

den Dikken, Marcel \& Anastasia Giannakidou. 2002. From Hell to Polarity: "Aggressively Non-D-Linked" Wh-Phrases as Polarity Items. Linguistic Inquiry 33(1). 31-61. doi:10.1162/002438902317382170.

Giannakidou, Anastasia. 1999. Affective dependencies. Linguistics and Philosophy 22. 367-421. doi:10.1023/A:1005492130684.

Groenendijk, Jeroen \& Martin Stokhof. 1984. Studies on the semantics of questions and the pragmatics of answers. Amsterdam, Netherlands: University of Amsterdam $\mathrm{PhD}$ dissertation.

Hamblin, Charles. 1973. Questions in Montague English. Foundations of Language 10. 41-53. doi:10.1016/B978-0-12-545850-4.50014-5.

Huang, C.-T. James \& Masao Ochi. 2004. Syntax of the hell: Two types of dependencies. In Moulton Keir \& Matthew Wolf (eds.), 34th Conference of the North Eastern Linguistic Society, 279-293.

Karttunen, Lauri. 1977. Syntax and semantics of questions. Linguistics and Philos- 
Wh-the-hell as domain restrictor

ophy 1. 3-44. doi:10.1007/BF00351935.

Kiss, Angelika. 2017. Meta-conversational since when-questions and the common ground. In Volha Petukhova \& Ye Tian (eds.), 21st Workshop on the Semantics and Pragmatics of Dialogue, 38-47. Saarbrücken: Saarland University.

Kotek, Hadas. 2018. Composing questions, vol. 80 Linguistic Inquiry Monographs. Cambrige, MA: MIT Press.

Kratzer, Angelika \& Junko Shimoyama. 2002. Indeterminate pronouns: the view from Japanese. In Y. Otsu (ed.), 3rd Tokyo Conference on Psycholinguistics, 1-25. Tokyo: Hituzi Syobo.

Lahiri, Utpal. 1991. Embedded interrogatives and predicates that embed them: MIT $\mathrm{PhD}$ dissertation.

Merchant, Jason. 2001. The Syntax of Silence (Oxford Studies in Theoretical Linguistics 1). Oxford University Press.

Obenauer, Hans-Georg. 1994. Aspects de la syntaxe a-barre: Effets d'intervention et mouvements des quantifeurs: Universite de Paris VIII $\mathrm{PhD}$ dissertation.

Oguro, Takeshi. 2017. The true nature of wh-the-hell phrases. In Stefan Huber \& Sonia Ramírez Wolmuth (eds.), 2nd Annual Tampa Workshop on Syntax, Semantics, and Phonology, vol. 4 (Tampa Papers in Linguistics 2), .

Pesetsky, David. 1987. Wh-in-situ: movement and unselective binding. In Eric J. Reuland \& Alice G.B. Ter Meulen (eds.), The representation of (in)definiteness, vol. 14 Current Studies in Linguistics, 98-129. Cambridge, MA: MIT Press.

Pires, Acrisio \& Heather Lee Taylor. 2007. The Syntax of Wh-In-Situ and Common Ground. In Annual Meeting of the Chicago Linguistic Society, vol. 43 2, 201215.

Rawlins, Kyle. 2008. (Un)conditionals: An investigation in the syntax and semantics of conditional structures: UC Santa Cruz PhD dissertation.

Rizzi, Luigi. 1990. Relativized Minimality. Cambridge, MA: MIT Press.

Roberts, Craige. 2012. Information structure in discourse: Towards an integrated formal theory of pragmatics. Semantics \& Pragmatics 5(6). 1-69. doi:http://dx.doi.org/10.3765/sp.5.6.

Rooth, Mats. 1992. A theory of focus interpretation. Natural Language Semantics 1(1). 75-116. doi:10.1007/BF02342617.

Rudin, Deniz. 2019. Head-Based Syntactic Identity in Sluicing. Linguistic Inquiry 50(2). 253-283. doi:10.1162/ling_a_00308.

Stepanov, Arthur \& Wei-Tien Dylan Tsai. 2008. Cartography and licensing of wh-adjuncts: a cross-linguistic perspective. Natural Language and Linguistic Theory 26. 589-638. doi:10.1007/s11049-008-9047-z.

Szabolcsi, Anna \& Frans Zwarts. 1993. Weak islands and an algebraic semantics of scope taking. Natural Language Semantics 1(3). 235-284. doi:10.1007/BF00263545. 
Joshua Martin

Harvard University Department of Linguistics

Boylston Hall, Cambridge MA 02138

joshuamartin@g.harvard.edu 